\title{
Vol. 67, No. 33
}

In the report "Assessment of Epidemiology Capacity in State

Health Departments — United States, 2017," on page 936, a

Table contained errors. The corrected Table is below.

TABLE. Epidemiology full-time equivalents (FTEs), by program area - Council of State and Territorial Epidemiologists Epidemiology Capacity Assessment, 50 states and the District of Columbia, 2017

\begin{tabular}{|c|c|c|c|c|c|}
\hline Program area & $\begin{array}{l}\text { FTEs currently filled } \\
\text { (\% of total) }\end{array}$ & Additional FTEs needed & 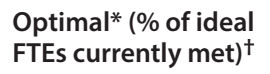 & Vacant positions ${ }^{\S}$ & $\begin{array}{l}\text { Positions actively } \\
\text { being recruited }\end{array}$ \\
\hline Infectious disease & 1,838.2 (54.6) & 338.4 & $2,176.6(84.4)$ & 158.6 & 140.6 \\
\hline Maternal and child health & $321.2(9.5)$ & 122.0 & $443.2(72.4)$ & 41.7 & 36.7 \\
\hline Chronic disease & $304.4(9.0)$ & 136.6 & $441.0(69.0)$ & 44.7 & 37.7 \\
\hline Environmental health & $221.7(6.6)$ & 121.9 & $343.6(64.5)$ & 23.3 & 18.3 \\
\hline Informatics & $95.7(2.8)$ & 91.2 & $186.9(51.2)$ & 11.2 & 13.2 \\
\hline Vital statistics & $110.7(3.3)$ & 62.0 & $172.7(64.1)$ & 15.0 & 14.0 \\
\hline Injury & $102.5(3.0)$ & 56.9 & $159.4(64.3)$ & 9.5 & 10.5 \\
\hline Preparedness & $117.6(3.5)$ & 35.7 & $153.3(76.7)$ & 13.2 & 13.2 \\
\hline Substance abuse & $58.6(1.7)$ & 63.7 & $122.3(47.9)$ & 8.8 & 6.3 \\
\hline Occupational health & $28.4(0.8)$ & 38.1 & $66.5(42.7)$ & 3.0 & 2.0 \\
\hline Mental health & $4.0(0.1)$ & 42.3 & $46.3(8.6)$ & 1.3 & 3.3 \\
\hline Oral health & $18.0(0.5)$ & 25.0 & $43.0(41.9)$ & 7.5 & 5.5 \\
\hline Genomics & $4.4(0.1)$ & 20.2 & $24.6(17.9)$ & 6.0 & 6.0 \\
\hline Other & $143.4(4.3)$ & 45.1 & $188.5(76.1)$ & 9.6 & 6.6 \\
\hline Total & $3,368.8(100.0)$ & $1,199.1$ & 4,567.9 (73.7) & 353.4 & 313.9 \\
\hline
\end{tabular}

* Currently filled plus additional needed.

${ }^{\dagger}$ Currently filled/ideal x 100 .

$\S$ Positions to be filled at a state health department for which work is available and the job could start within 30 days.

"Vacant positions human resources working actively to fill. 